\title{
ELECTROCHEMICAL REDUCING OF TERBIUM AND HOLMIUM IONS IN THE SODIUM AND POTASSIUM CHLORIDES MELT WITH EQUIMOLAR COMPOSITION
}

Vadym Kovalenko

Department of Analytical Chemistry and Chemical Technology of Food Additives and Cosmetics ${ }^{l}$ Competence center Ecological technologies and systems ${ }^{2 \prime}$ vadimchem@gmail.com

Olga Chernova

Department of Technology Inorganic Substances and Electrochemical Productions ${ }^{2}$ olgavc_kirov@mail.ru

Valerii Kotok

Department of Processes, Apparatus and General Chemical Technology ${ }^{1}$

Competence center Ecological technologies and systems ${ }^{2 \prime}$

valeriykotok@gmail.com

Sergey Zhykovin

Department of Technology Inorganic Substances and Electrochemical Productions ${ }^{2}$ zhykovin@mail.ru

Ihor Kovalenko

Department of Inorganic Chemistry ${ }^{1}$

il.kovalenko050@gmail.com

Denis Kondratyev

Department of Technology Inorganic Substances and Electrochemical Productions ${ }^{2}$ denis512a@mail.ru

Viktor Ved

Department of Equipment Of Chemical Plants

251277ved@gmail.com

Volodymyr Verbitskiy

National Ecology and Nature Center

19 Vyshgorods'ka str., Kyiv, 04074, Ukraine

National Pedagogical Dragomanov University

9 Pyrogova str., Kyiv, Ukraine, 01601

vladimir.verbitskiy@gmail.com

${ }^{1}$ Ukrainian State University of Chemical Technology

8 Gagarina ave., Dnipro, Ukraine, 49005

${ }^{2}$ Vyatka State University

36 Moskovskaya str., Kirov, Russian Federation, 610000

\section{Abstract}

Interest to rare-earth metals (REM) and their alloys is due to the possibility of using them for the creation of new materials need for modern technology. For instance, REM as alloying components allows for preparation of material with special magnetic properties. A promising method for forming such coating is the surface treatment of metals. This process has an electrochemical character as such for the organization of technology the knowledge of kinetics and mechanism of these processes is important. Despite significant interest in rare-earth metals, these issues are not well described in the literature. In order to choose an adequate mathematical model for calculation of kinetic primers, preliminary experiments that allow evaluating the reversibility of the elec- 
trode process have been conducted. Based on that, it was concluded that cathodic reduction of terbium and holmium ions in equimolar NaCl- $\mathrm{KCl}$ melt is irreversible. By means of voltammetric analysis, kinetic parameters (transfer coefficients, heterogeneous constants of charge transfer rate) of terbium and holmium electroreduction in equimolar $\mathrm{NaCl}-\mathrm{KCl}$ melt were determined. The experiment was conducted in a three-electrode cell under a purified argon atmosphere. A dependency of kinetic parameters on the concentration of terbium and holmium chlorides wt (\%): 1, 3, 5, 7, 10, was determined. The experiment was conducted in 1073-1173 K temperature range. Values of kinetic parameters increase with temperature but decrease with the increase of REM chloride. Based on obtained data, it was found that electroreduction of chloride complexes $\mathrm{LnCl}_{6}^{3-}(\mathrm{Ln}-\mathrm{Tb}, \mathrm{Ho})$ in equimolar $\mathrm{NaCl}-\mathrm{KCl}$ melt is irreversible in the studied range of temperatures and REM concentrations. In summary of experimental data, in range of temperature and rare-earth chloride concentration, and assumption was made that reduction of terbium and holmium ions occurs in two stages. The process includes the preceding stage of complex dissociation. A mechanism of $\mathrm{LnCl}_{6}^{3-}$ complex reduction in the mentioned melt is proposed. The obtained results are in agreement with literate data for analogues systems.

Keywords: chloride melts, terbium, holmium, kinetic parameters, voltammetry.

DOI: $10.21303 / 2461-4262.2019 .00980$

\section{Introduction}

Rare-earth compounds and alloys, namely holmium and terbium, possess unique chemical and physical properties, which makes them attractive for metallurgy, electrical engineering, atomic industry [1-3]. One of the promising methods for preparing of REM alloys is surface treatment in melts containing their salts. Effective control over the preparation of these alloys requires knowledge of kinetics and mechanism of cathodic reduction of terbium and holmium ions in salt melt electrolytes. In literature, there is no point of view on the mechanism of cathodic reduction of the rare-earth metal. Authors of works [4-6] assumed that the discharge mechanism is single-stage: $\mathrm{Ln}^{3+}+3 \mathrm{e} \rightarrow \mathrm{Ln}$. In papers $[7,8]$ researchers point out that reduction mechanism is two-stage: $\mathrm{Ln}^{3+}+\mathrm{e} \rightarrow \mathrm{Ln}^{2+} ; \mathrm{Ln}^{2+}+2 \mathrm{e} \rightarrow \mathrm{Ln}$. It is known that rare-earth elements in chloride melt form complexes with structure $\mathrm{LnCl}_{6}^{3-}, \mathrm{LnCl}^{4-}$ and $\mathrm{LnCl}_{4}^{2-}$. The aim of this work is a complex study on the cathodic reduction process of terbium and holmium. To acquire qualitative characteristics of REM ions discharge, study the influence of conditions (temperature and concentration) in equimolar $\mathrm{NaCl}-\mathrm{KCl}$ melt. The obtained data allows controlling electrochemical processes occurring in the molten system, which would expand the application of REM in different field of technology.

\section{Methods, materials, and instruments for voltammetry study of reduction kinetics of $\mathrm{TbCl}_{3}$ and $\mathrm{HoCl}_{3}$ in equimolar $\mathrm{NaCl}-\mathrm{KCl}$ melt}

2. 1. Materials for voltammetry study of reduction kinetics of $\mathrm{TbCl}_{3}$ and $\mathrm{HoCl}_{3}$ in equimolar NaCl-KCl melt

The experiment was conducted with the use of methods described in the literature $[9,10]$. To prepare the equimolar mixture, analytical grade sodium and potassium chlorides were vacuum dried and mixed in a specific proportion, and then were melted in a quartz cell. Melt was purged with dried hydrogen chloride for 2-3 hours. REM chlorides were dehydrated with carbon tetrachloride vapor according to the literature method [11]. Because the presence of moisture affects experimental results, its presence in chlorides of terbium and holmium was measured using Shimadzu DTG-60. After being exposed to air for less than a minute, moisture content was $0.4 \mathrm{wt} \%$ from initial weight.

\section{2. Instruments for voltammetry study of reduction kinetics of $\mathrm{TbCl}_{3}$ and $\mathrm{HoCl}_{3}$ in} equimolar $\mathrm{NaCl}-\mathrm{KCl}$ melt

The mechanism of cathodic reduction of terbium and holmium chloride was studied by means of voltammetry, with scan rate from 0.2 to $20 \mathrm{~V} / \mathrm{s}$. Voltammetry curves were recorded using potentiostat-galvanostat P-150I. A three-electrode cell was used in the experiment, with molybdenum working electrode and glassy carbon (SU-2000) crucible also serving as a counter electrode; reference electrode - lead electrode [12]. To prevent the entry of oxygen-containing compounds with the melt, alumina jacket of the lead electrode was coated with titanium nitride. 
The experiment was conducted in the temperature range of 1073-1173 K. Concentrations of holmium and terbium chlorides were, $\%$ wt.: $1 ; 3 ; 5 ; 7$ and 10 . To prevent the formation of oxychlorides, the rare-earth chloride samples were weighted in a sealed test tube. Crucible was placed into hermetically sealed fused quartz (Fig. 1).

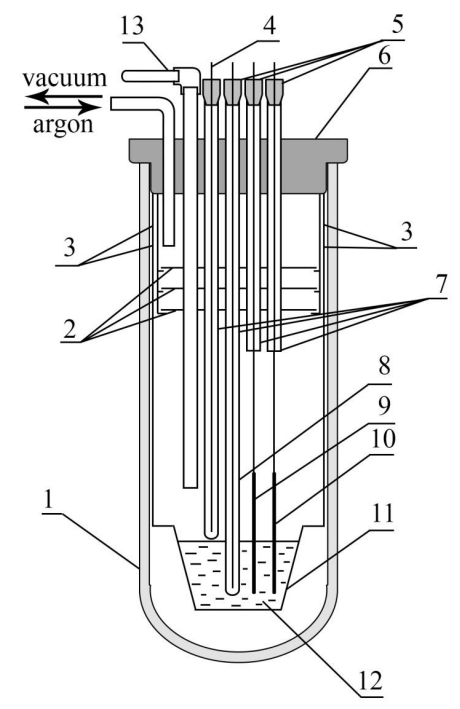

Fig. 1. Experimental cell: 1 - fused quartz cell; 2 - molybdenum shields; 3 - molybdenum holders; 4 - thermocouple (chromel-alumel); 5 - molybdenum current collectors;

6 - vacuum rubber plug; 7 - quartz tubes; 8 - reference electrode; 9 - working electrode;

10 - counter-electrode; 11 - crucible; 12 - melt; 13 - device for loading $\mathrm{TbCl}_{3}$ and $\mathrm{HoCl}_{3}$

The cell was heated using a vertical furnace with automatic temperature control. Before the experiment, the cell was hermetically sealed filled with argon. Terbium and holmium chlorides were added to the melt after the cell was filled with argon and heated to experimental temperature. After the experiment, the concentration of REM chloride in the solidified melt was measured by complex titration with Arsenazo I as an indicator.

\section{Results of studying electroreduction of $\mathrm{TbCl}_{3}$ and $\mathrm{HoCl}_{3}$ in equimolar $\mathrm{NaCl}-\mathrm{KCl}$ melt}

Voltammetry curves are shown in Fig. 2. There are no peaks on background voltammetry curves, which indicate the absence of admixtures in the melt. When terbium chloride (Fig. 2, a) and holmium chloride (Fig. 2, b) are added to equimolar $\mathrm{NaCl}-\mathrm{KCl}$ melt, a peak appears on voltammetry curve.

Reversibility was evaluated according to known criteria [13]. Knowing the nature of the deleted stage allows for a justified choice of formulas evaluating kinetic parameters.

Reversibility criteria in voltammetry are a potential difference of peak and half-peak [13], calculated from equation (1) for a reversible process.

$$
E_{p / 2}-E_{p}=2.20 \frac{R T}{z F}=\text { const }
$$

where $E_{p}$ - peak potential, $\mathrm{B} ; E_{p / 2}$ - half-peak potential, $\mathrm{B} ; z$ - number of electrons; $R$ - universal gas constant; $F$ - Faraday constant.

Comparison of calculated and experimental values of $E_{p / 2}-E_{p}$ at $V=5 \mathrm{~V} / \mathrm{s}$ are shown in Table 1. Similar values have been obtained for another condition of the experiments.

A significant difference between experimental and theoretical values allows concluding that the process occurs irreversibly. Analysis of cyclic voltammetry curves, namely difference between cathodic $\left(E_{c p}\right)$ and anodic $\left(E_{a p}\right): E_{a p}-E_{c p}=0.274 \mathrm{~B}$ (discharge of terbium ions) and $E_{c p}-E_{a p}=0.263 \mathrm{~B}$ (discharge of holmium ions), also indicates irreversibility of terbium and holmium discharge in 
equimolar $\mathrm{NaCl}-\mathrm{KCl}$ melt (Fig. 3). Our conclusion on the irreversibility of terbium and holmium discharge in chloride melts is in agreement with work [14].

Table 1

Experimental and calculated values of $E_{p / 2}-E_{p}, \mathrm{~V}$

\begin{tabular}{ccccccc}
\hline \multirow{2}{*}{ Depolarizer } & \multicolumn{2}{c}{$\begin{array}{c}\mathbf{C = 1} \text { \% wt. } \\
\mathbf{T = 1 0 7 3 ~ K}\end{array}$} & \multicolumn{2}{c}{$\begin{array}{c}\mathbf{C = 5} \% \mathbf{w t} \\
\mathbf{T}=\mathbf{1 1 2 3} \mathbf{~ K}\end{array}$} & \multicolumn{2}{c}{$\begin{array}{c}\mathbf{C = 1 0} \% \mathbf{w t} \\
\mathbf{T}=\mathbf{1 1 7 3} \mathbf{~ K}\end{array}$} \\
\cline { 2 - 7 } & theor. & exp. & theor. & exp. & theor. & exp. \\
\hline $\mathrm{TbCl}_{6}{ }^{3-}$ & 0.20 & 0.50 & 0.21 & 0.49 & 0.22 & 0.48 \\
$\mathrm{HoCl}_{6}{ }^{3-}$ & 0.20 & 0.46 & 0.21 & 0.46 & 0.22 & 0.47
\end{tabular}

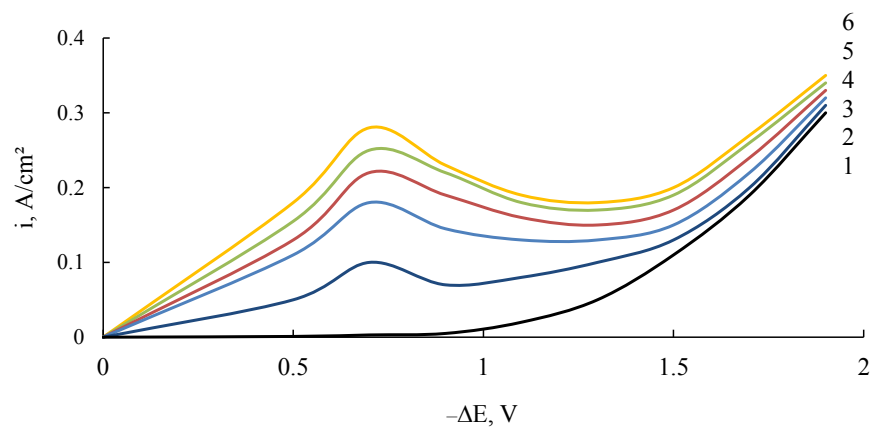

$a$

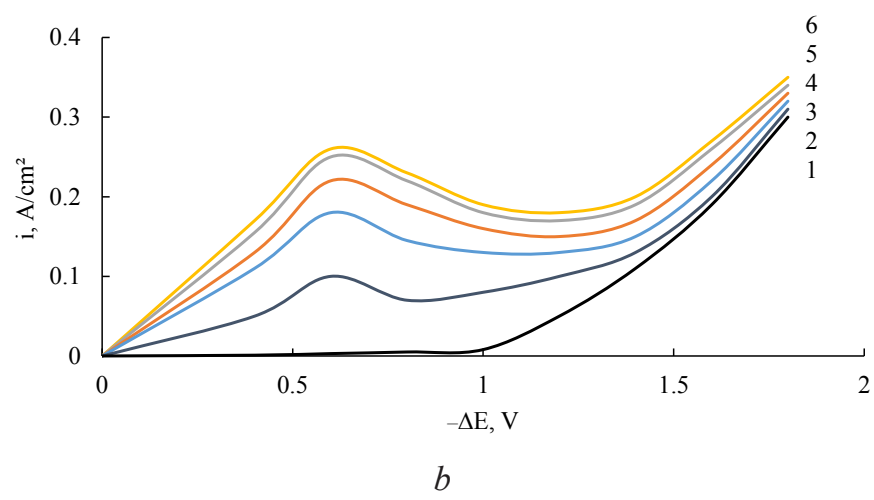

Fig. 2. Typical voltammetry curves (scan rate $1 \mathrm{~V} / \mathrm{s}(1-3)$ and $5 \mathrm{~V} / \mathrm{s}(4-6))$ : $a$ - backround curve of $\mathrm{NaCl}-\mathrm{KCl}$ melt (1), curve of $\mathrm{NaCl}-\mathrm{KCl}-\mathrm{TbCl}_{3}$ melt with different concentration $\mathrm{TbCl}_{3}(2-6)$, for $C=1 \%$ wt., $T=1073 \mathrm{~K}$ (2), $C=10 \%$ wt., $T=1173 \mathrm{~K}(3), C=1 \%$ wt., $T=1073 \mathrm{~K}$ (4), $C=5 \%$ wt., $T=1123 \mathrm{~K}(5), C=10 \%$ wt., $T=1173 \mathrm{~K}(6) ; b$ - background curve $\mathrm{NaCl}-\mathrm{KCl}$ melt (1), curve of $\mathrm{NaCl}-\mathrm{KCl}-\mathrm{HoCl}_{3}$ melt with different concentration $\mathrm{HoCl}_{3}(2-6)$, for $C=1 \%$ wt., $T=1073 \mathrm{~K}$ (2), $C=10 \%$ wt., $T=1173 \mathrm{~K}$ (3), $C=1 \%$ wt., $T=1073 \mathrm{~K}$ (4), $C=5 \%$ wt., $T=1123 \mathrm{~K}(5), C=10 \%$ wt., $T=1173 \mathrm{~K}$ (6)

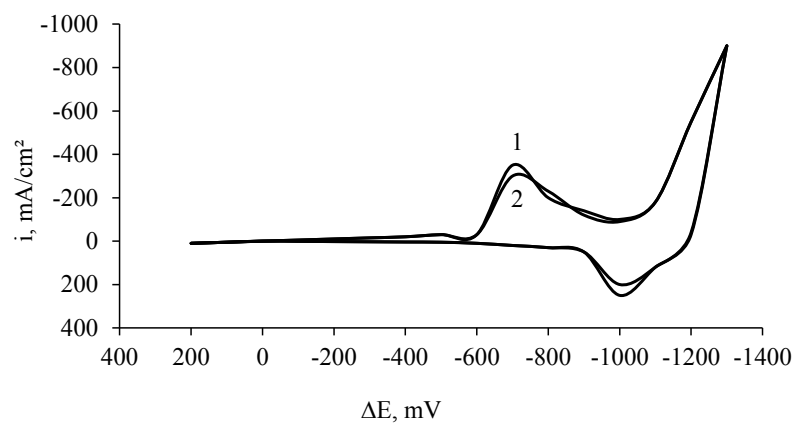

Fig. 3. Cyclic voltammetry curves of $\mathrm{NaCl}-\mathrm{KCl}+5$ wt. $\% \mathrm{LnCl}_{3}$, at $T=1123 \mathrm{~K}$ and scan rate of $0.5 \mathrm{~V} / \mathrm{s}: 1-\mathrm{TbCl}_{3}, 2-\mathrm{HoCl}_{3}$ 
Values $\alpha z$ and $k_{f h}^{0}$ for the irreversible process can be calculated from equation (2) [13].

$$
E_{P}=-1.14 \frac{R T}{\alpha z F}+\frac{R T}{\alpha z F} \ln \frac{k_{f h}^{0}}{D^{1 / 2}}-\frac{R T}{2 \alpha z F} \ln \alpha z V,
$$

where $\alpha z$ - transfer coefficient, $k_{f h}^{0}$ - heterogeneous constant of charge transfer rate.

Parameter calculation results are listed in Tables 2, 3 .

Table 2

Values of $\alpha z$

\begin{tabular}{|c|c|c|c|c|c|c|c|c|c|c|}
\hline \multirow{3}{*}{$T, \mathbf{K}$} & \multicolumn{10}{|c|}{ Concentration of REM chloride, \% (wt.) } \\
\hline & \multicolumn{2}{|c|}{1} & \multicolumn{2}{|c|}{3} & \multicolumn{2}{|c|}{5} & \multicolumn{2}{|c|}{7} & \multicolumn{2}{|c|}{10} \\
\hline & $\mathrm{TbCl}_{3}$ & $\mathrm{HoCl}_{3}$ & $\mathrm{TbCl}_{3}$ & $\mathrm{HoCl}_{3}$ & $\mathrm{TbCl}_{3}$ & $\mathrm{HoCl}_{3}$ & $\mathrm{TbCl}_{3}$ & $\mathrm{HoCl}_{3}$ & $\mathrm{TbCl}_{3}$ & $\mathrm{HoCl}_{3}$ \\
\hline 1073 & 0.63 & 0.58 & 0.55 & 0.54 & 0.54 & 0.48 & 0.54 & 0.54 & 0.55 & 0.54 \\
\hline 1098 & 0.65 & 0.63 & 0.62 & 0.61 & 0.59 & 0.61 & 0.58 & 0.54 & 0.58 & 0.54 \\
\hline 1123 & 0.65 & 0.64 & 0.63 & 0.60 & 0.60 & 0.59 & 0.57 & 0.55 & 0.58 & 0.53 \\
\hline 1148 & 0.69 & 0.65 & 0.65 & 0.61 & 0.62 & 0.58 & 0.60 & 0.60 & 0.59 & 0.59 \\
\hline 1173 & 0.70 & 0.68 & 0.66 & 0.61 & 0.65 & 0.63 & 0.64 & 0.63 & 0.60 & 0.60 \\
\hline
\end{tabular}

Table 3

Values of $k_{f h}^{0} 10^{3}, \mathrm{~cm} / \mathrm{s}$

\begin{tabular}{|c|c|c|c|c|c|c|c|c|c|c|}
\hline \multirow{3}{*}{$T, \mathbf{K}$} & \multicolumn{10}{|c|}{ Concentration of REM chloride, \% (wt.) } \\
\hline & \multicolumn{2}{|c|}{1} & \multicolumn{2}{|c|}{3} & \multicolumn{2}{|c|}{5} & \multicolumn{2}{|c|}{7} & \multicolumn{2}{|c|}{10} \\
\hline & $\mathrm{TbCl}_{3}$ & $\mathrm{HoCl}_{3}$ & $\mathrm{TbCl}_{3}$ & $\mathrm{HoCl}_{3}$ & $\mathrm{TbCl}_{3}$ & $\mathrm{HoCl}_{3}$ & $\mathrm{TbCl}_{3}$ & $\mathrm{HoCl}_{3}$ & $\mathrm{TbCl}_{3}$ & $\mathrm{HoCl}_{3}$ \\
\hline 1073 & 0.69 & 0.65 & 0.27 & 0.23 & 0.25 & 0.15 & 0.25 & 0.11 & 0.11 & 0.11 \\
\hline 1098 & 0.85 & 0.71 & 0.30 & 0.24 & 0.26 & 0.13 & 0.27 & 0.13 & 0.13 & 0.14 \\
\hline 1123 & 0.98 & 0.79 & 0.29 & 0.24 & 0.31 & 0.20 & 0.30 & 0.14 & 0.14 & 0.11 \\
\hline 1148 & 1.03 & 0.84 & 0.30 & 0.27 & 0.34 & 0.23 & 0.33 & 0.19 & 0.20 & 0.12 \\
\hline 1173 & 1.07 & 0.87 & 0.44 & 0.29 & 0.45 & 0.25 & 0.37 & 0.19 & 0.27 & 0.16 \\
\hline
\end{tabular}

From Tables 2, 3 it can be seen that with increasing temperature, $\alpha z$ and $k_{f h}^{0}$ increase, while decrease with increasing concentration, which is in agreement with the literature [22].

\section{Discussion of results of studying electroreduction of $\mathrm{TbCl}_{3}$ and $\mathrm{HoCl}_{3}$ in equimolar NaCl-KCl melts}

According to literature data, REM in chloride melts exists primarily in the form of the complex. Our previous study [15] revealed that the electrode process is complicated by the preceding chemical reaction. According to [13], the kinetic current is related to the dissociation of complexes and it was assumed that reaction preceding electrode process is the dissociation of $\mathrm{LnCl}_{6}^{3-}$ : $\mathrm{LnCl}_{6}^{3--}=\mathrm{LnCl}^{4-}+2 \mathrm{Cl}^{-}$.

Based on obtained values of $\alpha z<1$, it can be assumed that electroreduction of $\mathrm{LnCl}_{6}^{3-}(\mathrm{Ln}-\mathrm{Tb}$, $\mathrm{Ho}$ ) occurs in two stages. The first stage is $\mathrm{LnCl}_{4}^{-}+e \rightarrow \mathrm{LnCl}_{4}^{2-}$. Stage-wise process of REM ions is described in works [16-19]. During the experiment, one peak was observed on voltammeter curves. This allows assuming that the second stage of cathodic reduction of $\mathrm{LnCl}_{4}^{2-}$ to $\mathrm{Ln}$ occurs simultaneously with the reduction of sodium and potassium. In chloride melts, REM exists in the form of 
complex anions with coordination numbers of 6 and 4 [20, 21]. Reduction of terbium and holmium is complicated by chemical reaction, which is the dissociation of $\mathrm{LnCl}_{6}^{3-}$ into $\mathrm{LnCl}_{4}^{-}$.

Obtained data is in good agreement with previously data for salt melts obtained by other authors $[22,23]$.

\section{Conclusions}

Process of electroreduction of terbium and holmium at inert molybdenum electrode in equimolar $\mathrm{NaCl}-\mathrm{KCl}$ melt, have been studied by means of voltammetry.

Analysis of obtained voltammetry curves revealed that reduction of REM chloride complexes is irreversible at studied temperature and concentration ranges.

Kinetic parameters of terbium and holmium electroreduction at following conditions (temperature range $1073-1173 \mathrm{~K}$, concentration 1-10\% (wt.)) have been determined. For terbium electroreduction transfer coefficients are 0.54-0.70 (arb. unit), heterogeneous constants of charge transfer rate are $0.11 \cdot 10^{3}-1.07 \cdot 10^{3} \mathrm{~cm} / \mathrm{s}$, for holmium electroreduction transfer coefficients are $0.48-0.68$ (arb. unit), heterogeneous constants of charge transfer rate are $0.11 \cdot 10^{3}-0.87 \cdot 10^{3} \mathrm{~cm} / \mathrm{s}$.

In summary of obtained data on electroproduction of $\mathrm{LnCl}_{6}^{3-}(\mathrm{Ln}-\mathrm{Tb}, \mathrm{Ho})$ in equimolar $\mathrm{NaCl}-\mathrm{KCl}$ melt on molybdenum electrode, in 1073-1173 K temperature range and terbium chloride concentrations of $1-10 \mathrm{wt}$. \%, includes following stages:

$$
\mathrm{LnCl}_{6}^{3-} \rightarrow \mathrm{LnCl}_{4}^{-}+2 \mathrm{Cl}^{-}, \mathrm{LnCl}_{4}^{-}+e \rightarrow \mathrm{LnCl}_{4}^{2-} \text {. }
$$

\section{References}

[1] Giliarova, A. A. (2018). Rare earth metals: application of Hi-Tech and potential of Kola peninsula. Economics and business: theory and practice, $3,40-45$.

[2] Petrov, I. M., Naumov, A. V. (2012). The current state of the global market for rare earth metals and Russian prospects in this market. University news. Non-ferrous metallurgy, 2, 61-71.

[3] Kuznetsov, S. A. (2007). Electrochemistry of rare-earth, rare metals in salt melts and the synthesis of new compounds and functional materials based on them. Tez. reports XIV Vseross. conf. on physical chemistry and electrochemistry of ionic melts and solid electrolytes. Moscow: Ekaterinburg IVE UB RAS, 1, 110.

[4] Kushkhov, K. B., Chuksin, S. I., Zhanikaeva, Z. A. (2013). Electroreduction of neodymium and praseodymium ions in equimolar $\mathrm{KCl}-\mathrm{NaCl}$ and eutectic $\mathrm{KCl}-\mathrm{NaCl}-\mathrm{CsCl}$ melts at a tungsten electrode. Russian Metallurgy (Metally), 2013 (8), $610-616$. doi: https://doi.org/10.1134/s0036029513080077

[5] Castrillejo, Y., Bermejo, M. R., Díaz Arocas, P., Martínez, A. M., Barrado, E. (2005). Electrochemical behaviour of praseodymium (III) in molten chlorides. Journal of Electroanalytical Chemistry, 575 (1), 61-74. doi: https://doi.org/10.1016/j.jelechem. 2004.08.020

[6] Kushkhov, H. B., Kalibatova, M. N., Vindizheva, M. K., Mukozheva, R. A. (2017). The investigation of lanthanum-ions electroreduction on tungsten electrode in equimolar $\mathrm{NaCl}-\mathrm{KCl}$ melts at $\mathrm{T}=973 \mathrm{~K}$. Journal Melts, 2, 142-152.

[7] Novoselova, A. V., Smolenskii, V. V. (2013). Electrochemical and thermodynamic properties of lanthanides (Nd, Sm, Eu, Tm, Yb) in Alkali metal chloride melts. Radiochemistry, 55 (3), 243-256. doi: https://doi.org/10.1134/s1066362213030016

[8] Uehara, A., Fukasawa, K., Nagai, T., Fujii, T., Yamana, H. (2011). Separation of Nd metal by using disproportionation reaction of $\mathrm{Nd}(\mathrm{II})$ in molten chlorides. Journal of Nuclear Materials, 414 (2), 336-339. doi: https://doi.org/10.1016/j.jnucmat.2011.05.004

[9] Myrnov, M. V. (1973). Elektrodnye potentsialy v rasplavlennyh khloridah. Moscow: Nauka, 247.

[10] Polyakov, E. G., Stangrit, P. T. (1993). Methodical specifics of electrochemical research on halogenide melts with rare elements. Journal Melts, 2, 17-27.

[11] Revzin, G. E. (1967). Anhydrous chlorides of rare-earth elements and scandium. Methods for the production of chemical reagents and preparations: a collection. Moscow: IREA, 16, 124-129.

[12] Smirnov, M. V., Chebotin, V. N. (1970). Ion activity in molten salts. Trudy institute elektrokhimii UFAN SSSR, 16, 3-16.

[13] Galius, Z. (1974). Teoreticheskie osnovy elektrohimicheskogo analiza [Theoretical basics of electrochemical analysis]. Moscow: Mir, 552.

[14] Kushkov, Kh. B., Zhanikayeva, Z. A., Chuksin, S. I. (2009). Electroreduction of neodymium ions in chloride melts. Melts, 3 , $51-59$.

[15] Chernova, O. V., Zhykovin, S. V., Kondratyev, D. A. (2016). The kinetics of the recovery of holmium ions from equimolar melt NaCl-KCl. Symbol of Science, 4, 31-32. 
[16] Kushkhov, K. B., Vindizheva, M. K., Karashaeva, R. A., Tlenkopachev, M. R. (2010). A study of samarium ions electroreduction at various electrodes in $\mathrm{KCl}-\mathrm{NaCl}-\mathrm{CsCl}$ melt at T=823 K. Russian Journal of Electrochemistry, 46 (6), 691-701. doi: https:// doi.org/10.1134/s1023193510060145

[17] Qi, X., Zhu, H. M. (2005). Reduction behavior of cerium (III) ions in NaCl-2CsCl melt. Rare Metals, 24 (1), 8-14.

[18] Ivanov, A. B., Sobolev, A. A., Volkovich, V. A., Vasin, B. D. (2015). Electrochemical and spectro-electrochemical study of the ytterbium behavior in the molten eutectic mixture of sodium chloride and cesium chloride. Melts, 1, 56-63.

[19] Kushkhov, Kh. B., Vindizheva, M. K., Mukozheva, R. A., Tlenkopachev, M. R., Nafonova, M. N. (2012). Investigation of the electroreduction of lanthanum ions on a tungsten electrode in halide melts at $\mathrm{T}=823 \mathrm{~K}$. Melts, 1, 50-59.

[20] Astakhova, I. S., Goriushkin, V. F. (1992). Periodichnost izmenenia kristalograficheskih svoistv khloridov lantanidov [Periodicity of the change of crystallographic properties of lantanide chloride]. Zhyrnal neorganicheskoy khimii, 37 (4), 707-714

[21] Smyrnov, M. V. (1973). Elektrodnye potentsialy v rasplavlennyh khloridah [Electrode potentials in the melted chroride]. Moscow: Nauka, 1973. 247 p.

[22] Delimarskiy, Yu. K. (1978). Elekrokhimiya ionnyh rasplavov [Electrochemistry of the ionic melts]. Moscow: Metallurgiya, 248.

[23] Delimarskiy, Yu. K. (1980). Elekrokhimiya ionnyh rasplavov [Electrochemistry of the ionic melts]. Kyiv: Naukova dum$\mathrm{ka}, 328$. 